\title{
Oil/water separation by using the photopolymerized porous hydrophobic and oleophilic materials \\ By
}

\author{
Nadeem Baig*1,2, Tawfik A. Saleh ${ }^{1}$
}

${ }^{1}$ Chemistry Department, King Fahd University of Petroleum and Minerals, Dhahran 31261, Saudi Arabia.

${ }^{2}$ Center for Research Excellence in Desalination \& Water Treatment, King Fahd University of Petroleum and Minerals, Dhahran 31261, Saudi Arabia Email: nadeembaig@kfupm.edu.sa; nadeembaig38@gmail.com

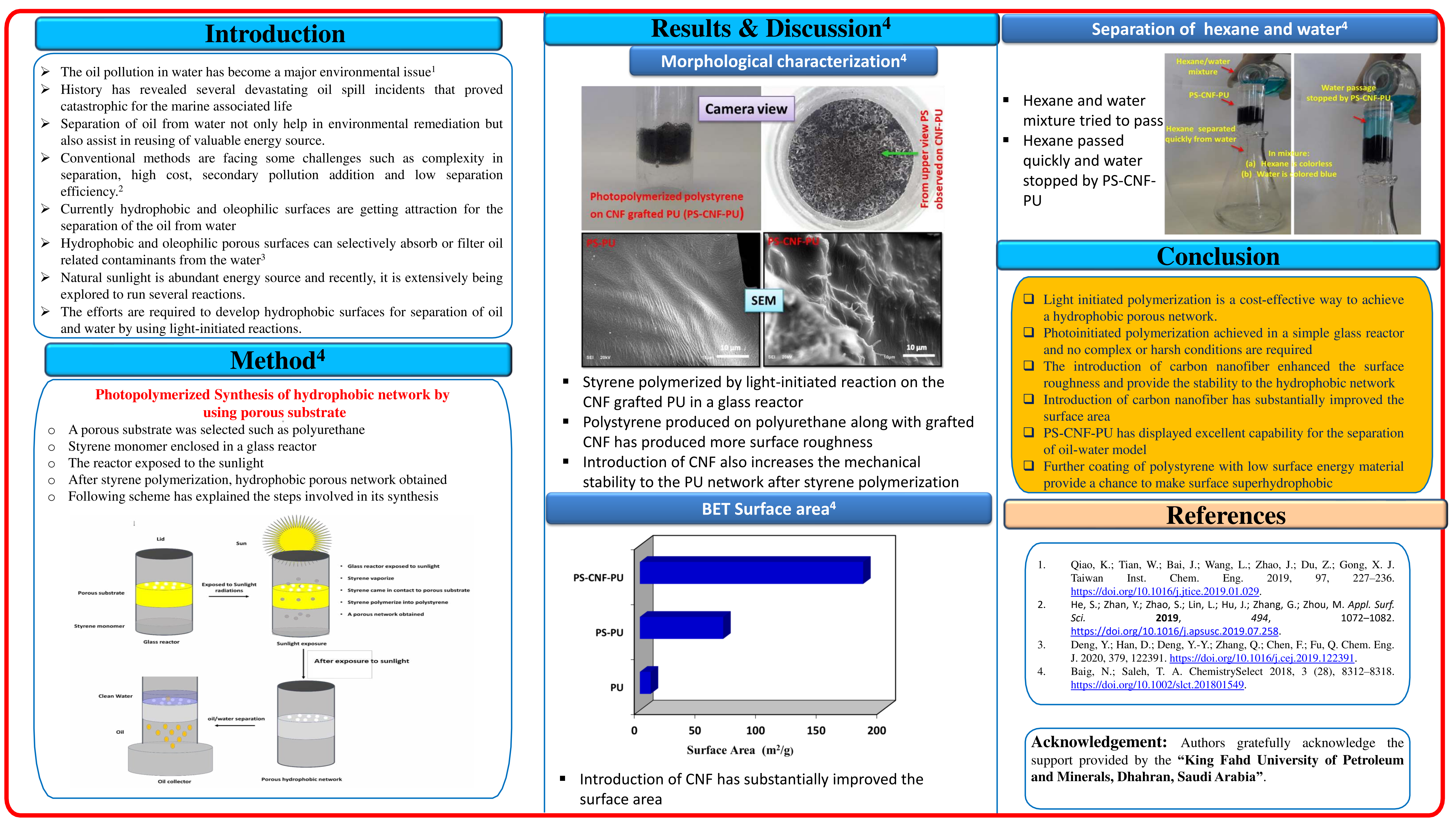

